\title{
High Genetic Addiction Risk Score (GARS) in Chronically Prescribed Severe Chronic Opioid Probands Attending Multi-pain Clinics: an Open Clinical Pilot Trial
}

\author{
Mark Moran ${ }^{1,2} \cdot$ Kenneth Blum ${ }^{2,3,4,5,6,7,8,9,10}$ (D) - Jessica Valdez Ponce ${ }^{2} \cdot$ Lisa Lott $^{2}$ - Marjorie C. Gondré-Lewis ${ }^{11}$. \\ Sampada Badgaiyan ${ }^{2} \cdot$ Raymond Brewer $^{2,8} \cdot$ B. William Downs ${ }^{9} \cdot$ Philip Fynman $^{12}$ - Alexander Weingarten ${ }^{12,13}$. \\ Jean Lud Cadet ${ }^{14}$. David E. Smith ${ }^{15}$. David Baron ${ }^{5}$. Panayotis K. Thanos ${ }^{16} \cdot$ Edward J. Modestino ${ }^{17}$. \\ Rajendra D. Badgaiyan ${ }^{18,19,20,21,22} \cdot$ Igor Elman $^{23} \cdot$ Mark S. Gold $^{24}$
}

Received: 16 July 2020 / Accepted: 25 January 2021 / Published online: 8 March 2021

(C) The Author(s) 2021

\begin{abstract}
Millions of Americans experience pain daily. In 2017, opioid overdose claimed 64,000 lives increasing to 84,000 lives in 2020, resulting in a decrease in national life expectancy. Chronic opioid use results in dependency, drug tolerance, neuroadaptation, hyperalgesia, potential addictive behaviors, or Reward Deficiency Syndrome (RDS) caused by a hypodopaminergia. Evaluation of pain clinic patients with the Genetic Addiction Risk Score (GARS) test and the Addiction Severity Index (ASI- Media Version V) revealed that GARS scores equal to or greater than 4 and 7 alleles significantly predicted drug and alcohol severity, respectively. We utilized RT-PCR for SNP genotyping and multiplex PCR/capillary electrophoresis for fragment analysis of the role of eleven alleles in a ten-reward gene panel, reflecting the activity of brain reward circuitry in 121 chronic opioid users. The study consisted of 55 males and 66 females averaging ages 54 and 53 years of age, respectively. The patients included Caucasians, African Americans, Hispanics, and Asians. Inclusion criteria mandated that the Morphine Milligram Equivalent (MME) was 30-600 mg/day (males) and 20 to $180 \mathrm{mg} /$ day (females) for treatment of chronic pain over 12 months. Ninety-six percent carried four or more risk alleles, and $73 \%$ carried seven or more risk alleles, suggesting a high predictive risk for opioid and alcohol dependence, respectively. These data indicate that chronic, legally prescribed opioid users attending a pain clinic possess high genetic risk for drug and alcohol addiction. Early identification of genetic risk, using the GARS test upon entry to treatment, may prevent iatrogenic induced opioid dependence.
\end{abstract}

Keywords Pain · Opioids $\cdot$ GARS $\cdot$ Hyperalgesia $\cdot$ Tolerance $\cdot$ Hypodopaminergia $\cdot$ Polymorphisms $\cdot$ Neuroadaptation $\cdot$ Genetic risk

\section{Introduction}

Non-cancerous pain treatment is challenging for primary care medicine. The USA has faced an iatrogenically induced opiate/opioid epidemic that has killed thousands, with as many as 110 dying daily from a narcotic overdose [1, 2]. While some argue that big pharma was not the culprit, we fervently disagree with this retort. The driver in the surge in drug overdose mortality rates has been greater use of prescription opioid analgesics. Unintentional drug overdose deaths

Kenneth Blum

drd2gene@gmail.com

Extended author information available on the last page of the article increased in 2007 to one every 19 minutes. Although initially more overdose deaths involved opioid analgesics than heroin and cocaine combined $[3,4]$, the recent availability of cheap street opiates has escalated heroin dependence [5-7]. By 2014, an NIH survey estimated that 25.3 million adults had pain every day for the preceding 3 months. In 2016-2017, many thousands of people died from opiate/opioid overdose, especially with the synthetic opioid fentanyl, which is more than 50 times more potent than other prescription opioids. To combat this growing threat to public safety, in 2016, new guidelines for prescribing opioids to chronic pain patients were issued by the Center for Disease Control (CDC) [6]. Morphine milligram equivalents declined by $29 \%$ in 2017, but more than 64,000 people still died from narcotic overdoses leading to a decrease in national life expectancy. Currently, nearly 116 million Americans suffer from chronic pain, 
according to the National Institute on Drug Abuse (NIDA). Those who suffer from severe pain are also likely to have worse overall physical and mental health status. Due to the role of big pharmaceutical industries in promoting opioid use and consequent addiction, the estimation is that they may have to pay $\$ 150$ billion in fines.

The recommendation to mandate genetic testing before treating pain with potent synthetic opioids is an attempt to reduce this problem. The rationale for this recommendation requires understanding the neurochemical interactions of cannabinergic-endorphinergic-glutaminergic-cholinergicdopaminergic systems (Fig. 1).

Figure 1 illustrates the interactions of 6 major neurotransmitter pathways within the brain reward cascade (BRC). Environmental stimulation in the hypothalamus causes serotonin release, which activates 5HT-2a receptors (green equal sign) that release opioid peptides from opioid peptidecontaining hypothalamic neurons. These opioid peptides have two distinct effects acting, presumably, through two different opioid receptors: (1) they (possibly enkephalin) bind to muopioid receptors located on GABAergic neurons of the Substantia Nigra; (2) they (beta-endorphin) can bind to delta opioid receptors to stimulate cannabinoid neurons (anandamide and 2-archydonoglcerol), with consequent inhibition of GABA neurons at the substantia nigra. Cannabinoids, primarily 2-archydonoglcerol, can indirectly disinhibit GABAA neurons in the substantia nigra through G1/0 coupled activation to CB1 receptors. Similarly, glutamate neurons in the dorsal raphe nuclei (DRN) can disinhibit GABAA neurons in the substantia nigra through GLU M3 receptors' activation. GABAA neurons can also inhibit VTA glutaminergic drive via GABAB3-containing neurons. Stimulation of ACH from cholinergic neurons in the nucleus accumbens can interact with both muscarinic and nicotinic receptors. Finally, VTA glutamate neurons that project to dopamine [DA] neurons can interact with NMDA receptors located on those neurons to cause dopamine release in the nucleus accumbens synaptic clefts.

Chronic opioid use results in clinical manifestations of dependency that include drug tolerance, hyper-analgesia, and potential addictive behaviors or reward deficiency syndrome (RDS) secondary to a hypodopaminergic state. However, there is a paucity of research related to the genetic risk or liability in chronic opioid users. A first step toward filling these holes was the investigation of the role of a reward gene panel, composed of ten genes and 11 risk-associated polymorphisms reflecting the brain reward circuitry, in 121 chronic opioid users attending several pain clinics in the USA. To accomplish this aim, we utilized RT-PCR for single nucleotide polymorphism (SNP) genotyping and multiplex PCR/ capillary electrophoresis for fragment analysis, across dopamine receptors (DRD1-4), dopamine transporter (DAT1), GABA-B3 receptor (GABRB3), monoamine oxidase A (MAOA), mu opiate receptor (OPRM1), serotonin receptor (SLC6A4), and catecholamine-O-methyl-transferase (COMT).

\section{Pharmacogenetics}

In terms of treatment efficacy and toxic consequences, each individual responds differently to each type of drug [7]. Factors that determine their responses include age, nutritional status, kidney and liver functions, concomitant illnesses, disease severity, and pathogenesis. Another factor is genetic variation (polymorphisms), which modifies the metabolism, efficacy, and toxicity of medications [8]. These inherited differences were first documented in the 1950s when genes that encode cholinesterase, the enzyme responsible for suxamethonium breakdown, unexpectedly caused prolonged muscle relaxation $[9,10]$. The second gene-based drug

Fig. 1 The brain reward cascade

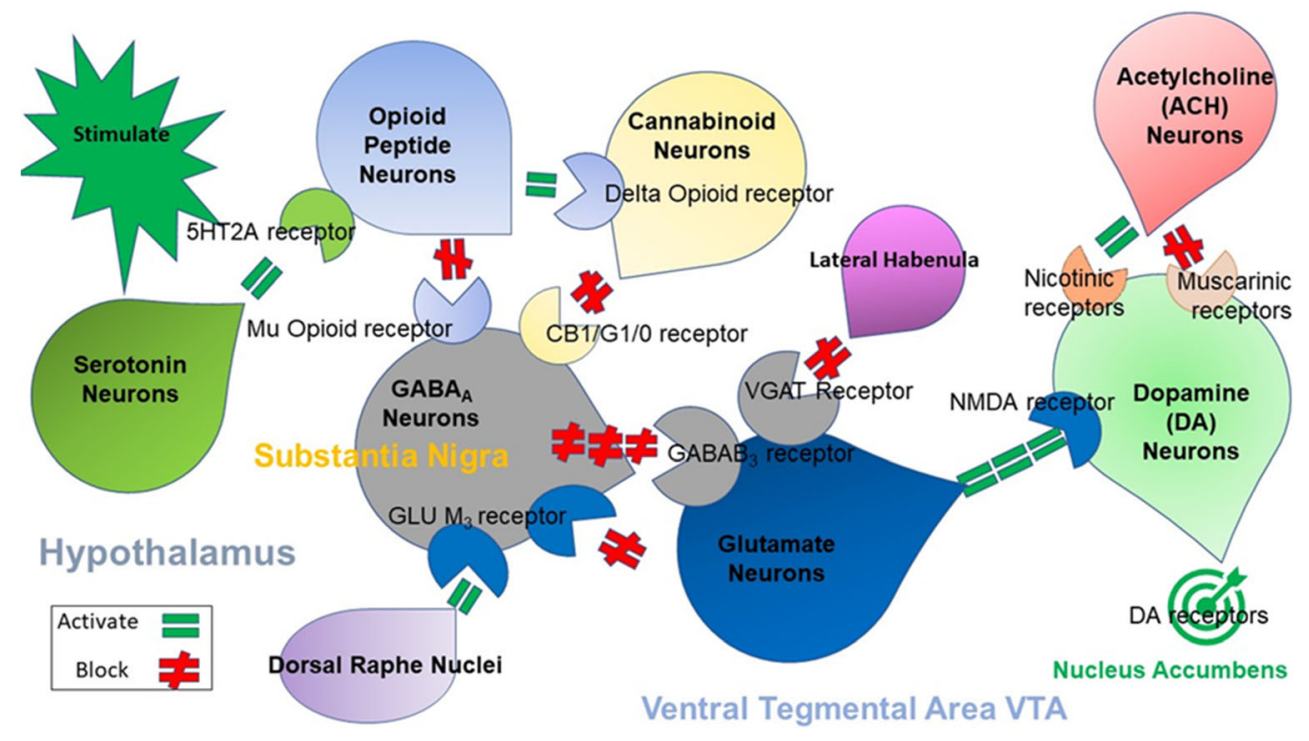


response was documented when some patients treated with anti-malarial therapy carried a gene variant that lowered the activity of blood cell glucose 6-phosphate-dehydrogenase and bled to death [11]. These observed differences in drug response gave rise to the field of "pharmacogenetics."

The genes that determine individual differences in drug response encode proteins. From 3 million unique DNA bases, these proteins form the molecular basis of cell cycle control and the synthesis or catabolism of structures like receptors, enzymes, and chemical messengers. These individual differences are due to gene variants of several genes involved in the multiple pathways of drug metabolism - individuals could carry gene variants that modify specific essential drug response-related proteins. The efficacy of medications will improve based on understanding specific molecular biological dysfunctions observable with accurate genotyping. Ongoing research and development that incorporates pharmacogenomics may lead to promising drug-based targets and make possible the design of effective novel medications.

Many molecular studies show that genetic polymorphisms modify sensitivity to specific medications. Notably, research concerning pharmacogenetic studies of opioid drugs is frequently reported and provides clinicians' help regarding medication dosing [12]. Information regarding genetic polymorphisms and inter-patient variability in response to opioid therapy, the disposition (pharmacokinetics), and pharmacology (pharmacodynamics) is documented [13]. The pharmacogenetics related to opioids receptors, transporters, and enzymes include the cytochrome P450s, the ABC family of transporters, and opioid receptors, and uridine diphosphoglucuronosyl-transferases.

However, while pharmacogenetics has its place in pain management, little is known about the role played by known polymorphisms associated with reward genes and subsequent genetic addiction risk. This question provided the impetus to perform the present open pilot clinical trial in severe chronic opioid users attending pain clinics [14].

\section{Understanding GARS}

The interaction of genes and neurotransmitters which control the release of dopamine is the brain reward cascade (BRC) [15] (see Fig. 1). Functional differences within the BRC, possibly genetic or epigenetic, may predispose individuals to addictive behaviors and altered pain tolerance [16]. The Genetic Addiction Risk (GARS) test is the first USA/European patented test clinically proven to predict vulnerability to pain and various other addictive and compulsive behaviors identified as reward deficiency syndrome (RDS).

Strategies to combat the opioid epidemic of prescription drug misuse and death and the implication of dopaminergic tone in pain pathways have been proposed previously [17]. The site of a predisposition to pain sensitivity may be the mesolimbic projection system, where genetic variations associate with pain vulnerability or tolerance [18]. These variations may provide specific targets to assist in the treatment of pain and identify risk for subsequent addiction. Many known gene variants are involved in, for example, opioid pharmacology, genetic testing of candidate genes like DRD1, 2, 3, 4, MOA-A, COMT, DAT1, SLC6A4, OPRM1, and GABRB3 might result in pharmacogenomics, personalized solutions, and improved clinical outcomes. Identifying those within compromised populations at genetic risk for RDS behaviors may be a frontline tool for better resource allocation in municipalities [19], especially in the criminal justice system.

The interaction of at least seven neurochemical pathways-serotonergic, GABAergic, endorphinergic, cannabinergic, glutaminergic, cholinergic, and dopaminergic - together constitute the "brain reward cascade" (see Fig. 1). This natural sequence of neurotransmission produces feelings of well-being. The cascade events, including the synthesis, vesicle storage, metabolism, release, and other neurotransmitter functions, are regulated by gene expression. Genetic testing of relevant variants can provide a window to an individual's neurochemistry, assisting providers to formulate optimal treatment options.

The release of dopamine, the neurotransmitter responsible for motivation and stress reduction, is the neurological reward cascade's functional endpoint. Consequently, genetically predisposed people with a hypodopaminergia seek out substances and behaviors to overcome this trait by activating mesolimbic brain dopaminergic centers [18, 20]. Lacking balanced dopamine function, an individual may have anhedonia, lack a sense of well-being, and may have difficulty with craving pleasure, lack of motivation, and coping with stress. Psychoactive substances and risky behaviors [21] induce DA release into the mesolimbic nucleus accumbens synapses to compensate for that individual's hypo-dopaminergic trait/state.

Temporary relief from the discomfort and a sense of wellbeing is the product of this self-medication [22]. Pathological substance-seeking behaviors are employed to provide a pleasurable response and to decrease uncontrollable cravings. Chronic misuse of substances often leads to inactivation, downregulation, and inhibition of neurotransmitter synthesis and neurotransmitter depletion. Those individuals with riskreward gene polymorphisms/variations, who experience environmental insults, will be at high risk for compulsive, impulsive, and addictive behaviors collectively referred to as reward deficiency syndrome (RDS), a spectrum that includes and characterizes genetically induced behaviors [23]. These pathological behaviors include addiction, tolerance, and dependence in chronic opioid use licit or illicit. The behavior or drug chosen by the individual is a function of both genetic and environmental factors such as availability of the drug and peer pressure. 
Fig. 2 The number of studies published in PUBMED in 2014 for each risk allele selected for the GARS panel

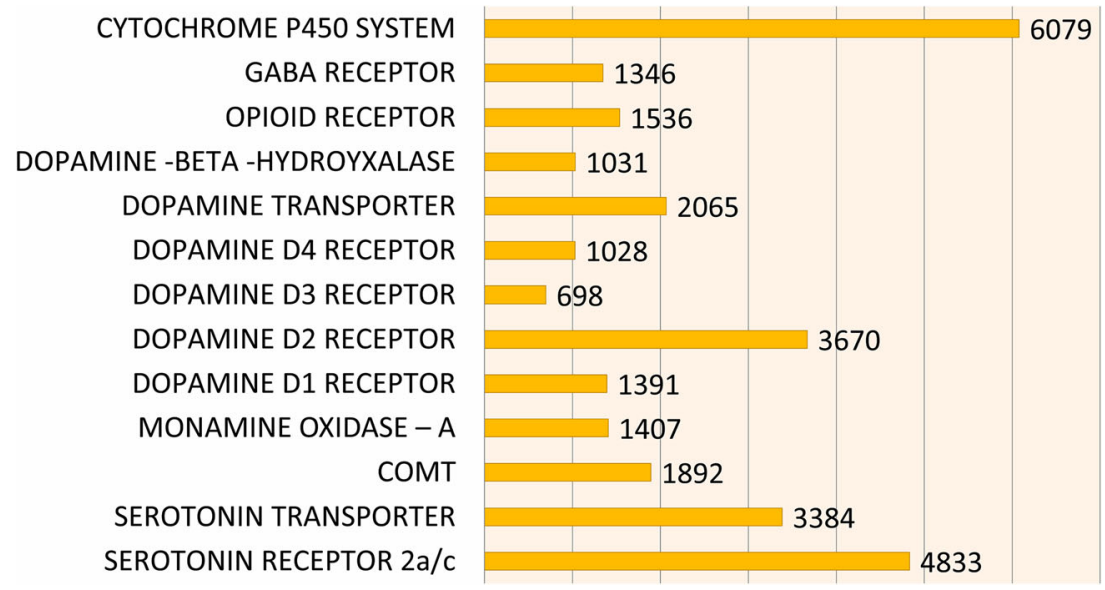

Initially, 11 polymorphisms in ten genes selected for the development of genetic addiction risk scores (GARS) test are alleles that contributed most to the hypodopaminergic trait RDS and were chosen following an extensive literature review. The selection involved thousands of studies associated alleles with significant risk for addictive behaviors, both drug and non-drug RDS (see Fig. 2). In previous research from Blum et al.,[24] evaluating 273 mixed-gender patients attending seven treatment centers who completed the Addiction Severity Index (ASI-Media Version V), GARS significantly predicted drug severity (equal or $>4$ alleles) and alcohol severity (equal or $>7$ alleles). This previous research served as the basis for the present open pilot clinical trial.

Figure 2 is a graph of the number of studies for each risk allele selected for the GARS panel, published in PUBMED 2014, and used at the time to develop the GARS test.

\section{Materials and Methods}

\section{Subjects and Demographics}

In this study, we carefully selected severe but stable, chronic opioid-dependent patients (at least 12 months) derived from several pain clinics from San Antonio and Austin, Texas, New York, and Idaho in the USA. A total of 121 participants were identified and enrolled in the present clinical trial.

Inclusion criteria mandated that the overall pain score must be 6 out of 10 . For the entire population, the average morphine equivalent (MME) must be $68 \mathrm{mg} / \mathrm{d}$, with a range of 20-600 $\mathrm{mg} /$ day. The MME for males must be $102 \mathrm{mg} / \mathrm{day}$, with a range of $30-600 \mathrm{mg} / \mathrm{d}$. The MME of females must be 45 $\mathrm{mg} / \mathrm{d}$ with a range of $20-180 \mathrm{mg} / \mathrm{d}$, and each patient selected had been treated in each pain clinic for at least 12 months.

Of the 55 males $(45 \%)$ and 66 females $(55 \%)$, ethnicities were $67 \%$ Caucasian, Hispanic (17\%), unknown classification (10\%), African-Americans (4\%), and Asian
(2\%). The average age for $M=54$ years (range 15-88) and for $F=53$ years (range 14-93) (see Table 1).

\section{Compliance with Ethical Standards}

Study protocols were reviewed and approved by the University of Vermont, School of Medicine (Burlington, VT) and PATH Foundation (NY) Institutional Review Boards (IRB). For patient privacy protection, the genotyping data conformed to standard HIPAA and Genetic Information Non-Discrimination Act (GINA) practices mandated by law and de-identified. The participants provided and approved written informed consent.

\section{Sample Collection and Processing}

Buccal cells were collected from each patient using an established minimally invasive collection kit, a sterile Copan 4N6FLOQ swab (Regular Size Tip In 109MM Long Dry Tube with Active Drying System). Subjects collected cells by rubbing the swab at least 25 times on both cheeks on each side of their mouth and then returned the swab to the specimen tube. Each respective pain clinic delivered the specimen tubes, labeled with a pre-defined

Table 1 Subject demographics

\begin{tabular}{llll}
\hline Population & All & Male & Female \\
\hline Number $(n)$ & 121 & $55(45 \%)$ & $66(55 \%)$ \\
$\begin{array}{l}\text { Average age }(n=121) \\
\text { Ethnicity }\end{array}$ & 53 & 54 & 53 \\
Caucasian & $67 \%$ & 36 & 45 \\
Hispanic & $17 \%$ & 8 & 13 \\
Unknown & $10 \%$ & 6 & 6 \\
Black or African American & $4 \%$ & 4 & 1 \\
Asian & $2 \%$ & 1 & 1 \\
\hline
\end{tabular}


Table 2 Single nucleotide polymorphisms (SNPs)

\begin{tabular}{llll}
\hline Gene & Polymorphism & Variant alleles & Risk alleles \\
\hline Dopamine D1 receptor DRD1 & $\mathrm{rs} 4532$ & $\mathrm{~A} / \mathrm{G}$ & $\mathrm{A}$ \\
Dopamine D2 receptor DRD2 & $\mathrm{rs} 1800497$ & $\mathrm{~A} / \mathrm{G}(\mathrm{A} 1 / \mathrm{A} 2)$ & $\mathrm{A}(\mathrm{A} 1)$ \\
Dopamine D3 receptor DRD3 & $\mathrm{rs} 6280$ & $\mathrm{C} / \mathrm{T}$ & $\mathrm{C}$ \\
Dopamine D4 receptor DRD4 & $\mathrm{rs} 1800955$ & $\mathrm{C} / \mathrm{T}$ & $\mathrm{C}$ \\
Catechol-O-methyltransferase COMT & $\mathrm{rs} 4680$ & $\mathrm{~A} / \mathrm{G}(\mathrm{Met} / \mathrm{Val})$ & $\mathrm{G}(\mathrm{Val})$ \\
Mu-opioid receptor OPRMI & $\mathrm{rs} 1799971$ & $\mathrm{~A} / \mathrm{G}(\mathrm{Asn} / \mathrm{Asp})$ & $\mathrm{G}(\mathrm{Asp})$ \\
\hline
\end{tabular}

bar-coded ID, to the Geneus Health Genomic Center for subsequent genotyping. Verified all steps of sample processing, used appropriate controls, including non-template controls and known DNA standards.

Tables 2, 3, 4, 5, and 6 index the genes and the specific risk polymorphisms included in the GARS panel. Each polymorphism was selected based on a known contribution to the RDS trait of hypodopaminergic functioning of the reward neurocircuitry. Capillary electrophoresis to detect AMELY and AMELX (AMELX's intron 1 contains a 6 bp deletion relative to intron 1 of AMELY) and PCR amplification determined the sex of DNA samples.

\section{Biotechnical Development of GARS Test}

Details about the biotechnical methods used to identify the (GARS) test alleles in Tables 2, 3, 4, 5, and 6 have been published previously $[25,26]$.

\section{Results}

\section{Allele and Genotype Frequencies, GARS Severity Scores}

Figure $3 \mathrm{a}$ and $\mathrm{b}$ are pie charts of the GARS genotyping displaying the results for 121 subjects in the study. Figure 3 a illustrates the percentage of the 121 patients predicted to have an elevated risk for drug addiction (96\%) by carrying at least 4 risk alleles; Figure $3 \mathrm{~b}$ illustrates the percentage predicted to have an elevated risk for alcohol addiction (73\%) by carrying at least 7 alleles.
In Fig. 3a, ninety-six (96\%) percent of 121 patients carried at least four hypodopaminergia risk alleles, and in Fig. 3b, $73 \%$ carried at least seven. Previous research from Blum et al. [24], evaluating 273 mixed-gender patients attending seven various treatment centers who completed the Addiction Severity Index (ASI-Media Version V) GARS significantly predicted drug severity (equal or $>4$ alleles) and alcohol severity (equal or $>7$ alleles).

Figure 4 reports the percentage of total calls (rank-ordered) that were risk alleles. While the DRD1 (rs 4532) at $88 \%$ ranked number 1 in terms of frequency, and the lowest risk allele was the DAT1 (rs 28363170) at 1\%, we found the following rank order for the tested variants: DRD1 (rs 4532)> MAOA (rs 768062321)> COMT (4680)> SLC6A4/ HTTLPR (rs 4795541, rs25531) > DRD4 (rs1800955)> GABRB3 (rs 764926719)> DRD3 (rs6280)> DRD2 (rs1800497)> DRD4 (rs 761010487)> OPRM1 (rs 1799971) $>$ and DAT1 (rs 28363170). Figure 5 reports both heterozygous and homozygous analyses for each gene related to the prevalence of GARS risk. Refer to Table 2 for specifics about risk and non-risk variants.

Figures 4 and 5 represent the aggregate patient information for each gene in the GARS panel. Genotyping results include information about homozygosity and heterozygosity within the cohort.

\section{Discussion}

The basis of the selection of the 121 patients was by the attending pain physician based on the mandated criteria detailed above as well as an additional criterion, namely, that the
Table 3 Simple sequence repeats (variable number tandem repeats and insertion/deletions)

\begin{tabular}{llll}
\hline Gene & Polymorphism & Variant alleles & Risk alleles \\
\hline Dopamine D4 receptor DRD4 & rs761010487 & 48bp repeat 2R-11R & $\geq 7 \mathrm{R}$, long form \\
Dopamine active transporter DAT1 & rs28363170 & 40p repeat 3R-11R & $<9 \mathrm{R}$ \\
Monoamine oxidase A MAOA & rs768062321 & 30bp repeat 2R-5R & $3.5 \mathrm{R}, 4 \mathrm{R}, 5 \mathrm{R}$ \\
Serotonin transporter & rs4795541, & 43bp repeat, with SNP L/XL & S, LG \\
SLC6A4 (5-HTTLPR) & rs25531 & and S, G/A & \\
\hline
\end{tabular}


Table 4 Dinucleotide repeats

\begin{tabular}{llll}
\hline Gene & Polymorphism & Variant alleles & Risk alleles \\
\hline GABA(A) receptor, Alpha-3 GABRB3 & Rs764926719 & CA dinucleotide repeat 171-201bp sized fragments & 181 \\
\hline
\end{tabular}

patient had to be stable with no positive urine screens for nonprescribed illicit drugs of abuse but not alcohol during urine screens. Indeed, a number of these individuals have shown periods of intoxication when attending the treatment center. The finding that $96 \%$ of these severe, chronic opioiddependent patients showed a high GARS in this cohort may, at first glance, may be somewhat surprising, but it does support the hypothesis that concomitant chronic opioid users would have a high GARS score. It is somewhat surprising that the frequency of the OPRM1 allele occurred in these patients at the rate of $27.27 \%$ [27]. The belief that this finding could suggest that the real phenotype even in OUD (legal or possibly illicit) is not merely linked to the primary-opioid type of receptors but rather to generalized reward genes influencing overall dopamine release. If the general phenotype is confirmed to be hypodopaminergia rather than any individual allele (like OPRM1), then this will help pinpoint novel therapeutic targets. The US National Institute of Mental Health (NIMH) has introduced the Research Domain Criteria (RDoC) project [28] to overcome inadequacies of the DSM involved in focus on symptoms, and the division of psychiatric disorders, including pain issues, into distinct categories. The RDoC uses five brain systems as impaired domains in different psychiatric conditions. This alternative framework will influence neuroscience research to use current understanding of behavior-brain relationships as the starting point for clinical phenomenology.

There have been other studies by Blum et al. [29] showing the high prevalence of risk alleles such as the DRD2 Taq A1 in obesity and comorbid substance use disorder (SUD). Outpatient from Princeton, NJ, neuro-psychiatric clinic, were genotyped for presence or absence of the Taq A1 allele. They found the DRD2 A1allele present in $73.9 \%$ of the obese subjects with comorbid SUD and $23.5 \%$ of obese subjects with no SUD. While these studies do not relate directly to pain issues or genetics and epigenetics, they point out that addiction vulnerability to all addictive behaviors as subtypes of RDS is positively affected by genetic vulnerability independent of substance. For example, Blum's group assessed substance use severity; they found that drug use increased with the Taq A1 allele prevalence. Of the less severe cases, $66.67 \%(8 / 12)$ possessed the A1 allele compared with $82 \%$ (9/11) of the most severe cases. Increasing drug use was positively and significantly associated with A1 allelic classification $(p<0.00001)$ in a linear trend analysis.

These data suggest that presence of the DRD2 A1 allele's bolsters the risk for obesity and other related addictive behaviors (previously referred to as the reward deficiency syndrome). The study also confirms that a BMI over 25 by itself (without comorbid SUD) is not a sufficient criterion for association with the DRD2 A1 allele. An increase in addiction severity increases the prevalence of at least the DRD2 A1 allele, especially in Japanese alcoholics [30]. Arinami et al. [31] also found that the proportions of subjects with more severe alcoholism in the Japanese alcoholics (7 out of 7), $100 \%$ processed A1/A1, $62 \%$ (26 out of 42 ) had A1/A2, and $48 \%$ (10 out of 21 ) were least severe A2/A2. Importantly, when one considers the addiction risk severity issue as
Table 5 GARS single nucleotide polymorphism assay information

\begin{tabular}{|c|c|c|}
\hline Assay ID & Gene and SNP & Context sequence \\
\hline \multirow[t]{2}{*}{ C___1011777_10 } & $D R D 1$ rs 4532 & TCTGATGACCCCTATTCCCTGCTT [G/A] \\
\hline & & GGAACTTGAGGGGTGTCAGAGCCCC \\
\hline \multirow[t]{2}{*}{ C___7486676_10 } & DRD2, ANKK1 rs 1800497 & CACAGCCATCCTCAAAGTGCTGGTC $[\mathrm{A} / \mathrm{G}]$ \\
\hline & & AGGCAGGCGCCCAGCTGGACGTCCA \\
\hline \multirow[t]{2}{*}{ C___949770_10 } & $D R D 3$ rs 6280 & GCCCCACAGGTGTAGTTCAGGTGGC $[\mathrm{C} / \mathrm{T}]$ \\
\hline & & ACTCAGCTGGCTCAGAGATGCCATA \\
\hline \multirow[t]{2}{*}{ C__ 7470700_30 } & DRD4 rs1800955 & GGGCAGGGGAGCGGGCGTGGAGGG [C/T] \\
\hline & & GCGCACGAGGTCGAGGCGAGTCCGC \\
\hline \multirow[t]{2}{*}{ C__25746809_50 } & COMT rs4680 & CCAGCGGATGGTGGATTTCGCTGGC [A/G \\
\hline & & TGAAGGACAAGGTGTGCATGCCTGA \\
\hline \multirow[t]{2}{*}{ C__8950074_1_ } & OPRM1 rs1799971 & GGTCAACTTGTCCCACTTAGATGGC [A/G] \\
\hline & & ACCTGTCCGACCCATGCGGTCCGAA \\
\hline
\end{tabular}


Table 6 GARS repeats primer details

\begin{tabular}{llll}
\hline Primer & Sequence $\left(5^{\prime}\right.$ to $\left.3^{\prime}\right)$ & 5' Label & Reaction (nM) \\
\hline AMELO-F & CCC TGG GCT CTG TAA AGA ATA GTG & NED & \multirow{2}{*}{150} \\
AMEL0-R & ATC AGA GCT TAA ACT GGG AAG CTG & - & \multirow{2}{*}{ NED } \\
MAO-F & ACA GCC TGA CCG TGG AGA AG & - & \\
MAO-R & GAA CGG ACG CTC CAT TCG GA & 6FAM & \multirow{2}{*}{120} \\
DAT-F & TGT GGT GTA GGG AAC GGC CTG AG & - & \multirow{2}{*}{480} \\
DAT-R & CTT CCT GGA GGT CAC GGC TCA AGG & VIC \\
DRD4-F & GCT CAT GCT GCT GCT CTA CTG GGC & - & \multirow{2}{*}{120} \\
DRD4-R & CTG CGG GTC TGC GGT GGA GTC TGG & NED \\
GABRA-F & CTC TTG TTC CTG TTG CTT TCA ATA CAC & - & 120 \\
GABRA-R & CAC TGT GCT AGT AGA TTC AGC TC & PET & \\
HTTLPR-F & ATG CCA GCA CCT AAC CCC TAA TGT & - & \\
HTTLPR-R & GAG GGA CTG AGC TGG ACA ACC AC &
\end{tabular}

discussed earlier by Noble et al. [32] who reported that the number of brain DA D2 receptors was a function of genotype where $\mathrm{A} 1 / \mathrm{A} 1$ had the highest reduction of DRD2 receptors compared with A1/A2 and A2/A2. These data support the concept that the DRD2 gene alone is associated with high addiction risk rates related to GARS selective risk alleles. Our finding in this cohort showed that the DRD2 A1 allele occurred in almost $1 / 3$ of the population supports its continued importance even in legal chronic opioid users.

The finding of the highest frequency observed in this cohort, the DRD1 allele at $87.60 \%$, is somewhat surprising, but if this holds up with a much larger OUD population, it may be a promising therapeutic target. Concerning the DRD1 allelic polymorphism as the most frequent allele, rs4532 studies by Liu et al. found evidence that SNPs related to DRD1 show an association with Chinese heroin dependence [33]. Other work by Peng et al. [34] found that single nucleotide polymorphisms (SNPs) of the DRD1 gene may be associated with the rapidity of the development of heroin dependence after the first opioid drug use. Of relevance to our present pilot study, the work of Zhu et al. [35] showing that for human carriers of the DRD1 rs4532, the duration of the transition from the first use to dependence (DTFUD), subjective pleasure responses to opioid on first use and post-dependence use and their opioid dependence overdose risk was significantly associated with the frequency of the DRD1 rs4532 allele. Our finding of a high (87.60.0\%) frequency of this allele in our present cohort is in complete agreement with Zhu et al. [35].

Additionally, Mayer-Blackwell et al. [36] found that oxycodone altered MAOA expression (found in this human study to have the second-highest frequency of $75.21 \%$ ) in the dorsal striatum of high preferring alcohol C57BL/6J mice. However, there is a paucity of research involving high MAOA activity and chronic opioid use. With this stated, we have no explanation for the low presence of the DAT1 (dopamine transporter) rs28363170. Of interest, carriers of DAT1 rs28363170, as researched by Brewer et al. [37], showed that carriers of the 9-allele of the DAT1 3'-untranslated region [9,9 and 9,10] exhibited greater responses to cocaine for "high," "any drug effect," "anxious," and "stimulated" (all $p$-values<0.001) compared with individuals homozygous for the 10 -allele. However, more research is required in a larger cohort of pain patients presenting with chronic opioid use to determine if our finding of a low frequency of the DAT1 9-allele confers a four times greater DA synaptic reabsorption rate than the more common 10 allele.

This legal dilemma of the prescription of potent analgesics (like OxyContin $®$ ), possibly the main gateway to opioid
Fig. 3 Percentage of 121 chronic pain patients predicted to carry elevated risk to drug (a) and alcohol (b) addiction based on the GARS genetic test

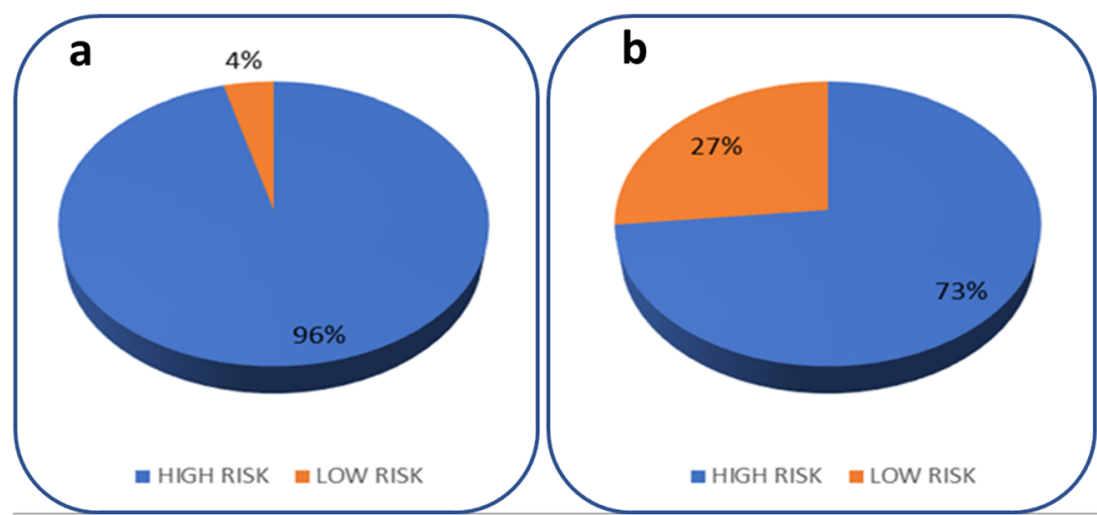


Fig. 4 Ranking of GARS risk alleles by allele frequency

\begin{tabular}{|c|c|c|c|}
\hline Rank Order & Gene & Polymorphism & Frequency \\
\hline 1 & $D R D 1$ & rs 4532 & $87.60 \%$ \\
\hline 2 & MAOA & rs768062321 & $75.21 \%$ \\
\hline 3 & $H T T L P R$ & rs4795541,rs25531 & $73.55 \%$ \\
\hline 4 & COMT & rs 4680 & $73.55 \%$ \\
\hline 5 & $D R D 4$ & rs1800955 & $66.12 \%$ \\
\hline 6 & GABRB3 & rs764926719 & $61.16 \%$ \\
\hline 7 & DRD3 & rs 6280 & $57.02 \%$ \\
\hline 8 & $D R D 2$ & rs1800497 & $42.98 \%$ \\
\hline 9 & DRD4 & rs761010487 & $34.71 \%$ \\
\hline 10 & OPRM1 & rs1799971 & $27.27 \%$ \\
\hline 11 & DAT1 & rs 28363170 & $0.83 \%$ \\
\hline
\end{tabular}

addiction and abuse, could be prevented using the GARS test is to determine the risk for opioid dependence. Pain patients at risk of OUD could be treated with non-steroid analgesics and other forms of pain relief, such as electrotherapy, and avoid using opioid compounds.

Blum's laboratory [38] proposed that any disturbance along the reward cascade (see Fig. 1), which might be due to either gene variations (polymorphisms) and environmental influences (epigenetics), can result in various addictive and other RDS behaviors. Despite the continued global search for specific candidate genes or clusters characterized by highdensity SNP arrays and Genome-Wide Association Studies (GWAS), it is common knowledge that many attempts have failed to replicate or have been inconclusive. However, Palmer et al. [39] recently showed that between 25 and $36 \%$ of the genetic variance in the generalized vulnerability to substance dependence might be attributable to common rather than rare SNPs. Moreover, the effect of common SNPs is additive when shared across principal indicators of various comorbidities. As a result of such research studies [21-24, 27, 29-34, 40], growing evidence supports specific gene variants, which may account for risk-prediction.
Blum's laboratory adopted a Bayesian approach [40] to establish that a positive predictive value (PPV) of $74 \%$, specifically for the A1 variant of the D2 allele, appeared to be an indication that if a child is born with this polymorphism, they will have a much higher risk of future RDS behaviors at some point in their lives. Since the 1990 finding of the association of the TaqA1 allele of the DRD2 gene and severe alcoholism [38], laboratories across the globe, including NIDA and NIAAA, have confirmed this early work [21, 41] and extended the importance of various candidate genes and even second messengers in the reward system.

It is strategic to cautiously accept that obtaining better treatment results may stem from identifying reward circuitry gene polymorphisms linked to dopaminergic pathways and opioid receptors. Understanding the relationship between reward circuitry participation in chronic opioid outcomes and corresponding genotypes provides an innovative model to improve opioid replacement therapy and enhance a patient's clinical experience [42], as suggested previously. Importantly, work from Gardner's group [43] at NIDA showed that by using dopamine D3 receptor-knock-out (D3-KO) mice, low D3R availability in the brain represents a risk factor for the
Fig. 5 Prevalence of GARS risk polymorphisms for 121 chronic pain patients

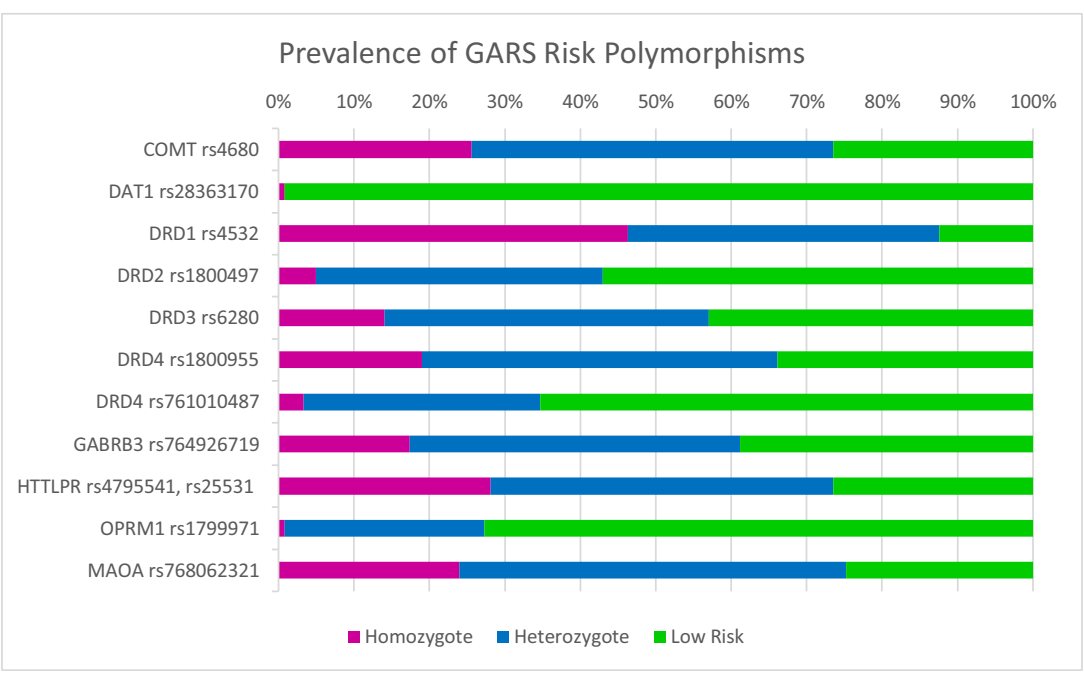


development of opioid abuse and addiction. This mouse data is in complete agreement with the findings of the present study.

Most importantly, while it is understood that opioids will have epigenetic effects on mRNA transcription and genetic expression of these risk alleles, our study only focuses on DNA polymorphisms. There are no alterations to these DNA polymorphisms, and thus the analysis of DNA can be done anytime during a person's lifespan. The take-home message is that utilizing GARS upon entry into a pain clinic to predict risk for opioid-induced dependence vulnerability is preferable. While only $4 \%$ of this cohort did not display vulnerability to risk as identified via GARS testing and in all likelihood are dependent on opioids after a long-term ( $\geq 12$ months), future studies would be most beneficial on people who do not carry the DNA polymorphic risks as a way of understanding potential protective mechanisms. Also, in a larger cohort, it may help explore racial and gender differences in risk for opioid dependence. Presently, there is significant evidence, for example, that specific genotypes such as A118G polymorphism of the OPRM1 gene caused different morphine consumption in female patients after total knee replacement [44-49].

\section{Summary}

As shown in this cohort of pain patients, the GARS test represents a panel of the known brain reward genes and associated risk polymorphisms that bestow an increased genetic risk for addiction and other RDS behaviors and can be useful for medical monitoring and clinical outcome response measures [42]. The take-home message derived from this pilot open clinical trial is that these findings must be considered when deciding about drug prescription, especially to treat pain sensitivity, and the development of therapeutic approaches. More research to expand our results to other populations that may or may not meet DSM criteria for SUD is required [50, 51].

Acknowledgements The authors appreciate the expert edits by Margaret A. Madigan and the staff of the Pain Consultants of San Antonio. We acknowledge the assistance of Mathew Schocket, MD, of the Capitol Pain Institute and Axis Spine Clinic in Idaho. Raw data is available from Geneus Health LLC; contact Raymond Brewer, MD.

Author Contribution Drs. Blum and Moran contributed equally. All other authors who worked on clinical assessment and data acquisition, analysis, and interpretation of data provided critical comments. All authors approved the publication of this article.

Funding Dr. Elman is supported by grant \# 1 I01 CX001118-01A2. Dr. Thanos is funded by the NY Research Foundation (RIAQ0940) and the NIH (DA035923 and DA035949). Dr. Badgaiyan is supported by the National Institutes of Health grants 1R01NS073884 and 1R21MH073624, and VA Merit Review Awards CX000479 and CX000780. Dr. Blum and Marjorie C. Gondre-Lewis are funded in part by NIH/NIMHD grant R41MD12318.

\section{Declarations}

Conflict of Interest Kenneth Blum is the inventor of genetically related patents. Dr. David E. Smith is on the Scientific Advisory Board for Geneus Health. Dr. Blum is Chief Scientific Officer at Geneus Health and GARS IP., LLC, and Raymond Brewer is Chief Medical Officer. Jessica Valdez-Ponce is the director of Geneus Laboratory, and Lisa Lott is a paid consultant. Raymond Brewer, MD, is the Chief Medical Officer of Genus Health. B. William Downs is the CEO of Victory Nutritional International, a licensee of Geneus Health. Dr. Sampada Badgaiyan is a consultant for Geneus Health, LLC. There are no other conflicts by any other author.

Open Access This article is licensed under a Creative Commons Attribution 4.0 International License, which permits use, sharing, adaptation, distribution and reproduction in any medium or format, as long as you give appropriate credit to the original author(s) and the source, provide a link to the Creative Commons licence, and indicate if changes were made. The images or other third party material in this article are included in the article's Creative Commons licence, unless indicated otherwise in a credit line to the material. If material is not included in the article's Creative Commons licence and your intended use is not permitted by statutory regulation or exceeds the permitted use, you will need to obtain permission directly from the copyright holder. To view a copy of this licence, visit http://creativecommons.org/licenses/by/4.0/.

\section{References}

1. Hall AJ, Logan JE, Toblin RL, Kaplan JA, Kraner JC, Bixler D, Crosby AE, Paulozzi LJ (2008) Patterns of abuse among unintentional pharmaceutical overdose fatalities. Jama 300(22):26132620. https://doi.org/10.1001/jama.2008.802

2. CDC (2011) Policy impact: prescription painkiller overdoses. Available from: https://www.cdc.gov/drugoverdose/pdf/

3. Black RA, Trudeau KJ, Cassidy TA, Budman SH, Butler SF (2013) Associations between public health indicators and injecting prescription opioids by prescription opioid abusers in substance abuse treatment. J Opioid Manag 9(1):5-17. https://doi.org/10.5055/jom. 2013.0142

4. Centers For Disease Control and Prevention, Public Health Service USDOH, Human Services. Guideline for Prescribing Opioids for Chronic Pain. J Pain Palliat Care Pharmacother 2016;30(2):138140

5. Lynch M (2013) Nonmedical use of prescription opioids: what is the real problem? Pain Res Manag 18(2):67-68. https://doi.org/10. $1155 / 2013 / 824914$

6. Centers For Disease C, Prevention Public Health Service USDOH, Human S (2016) Guideline for prescribing opioids for chronic pain. J Pain Palliat Care Pharmacother 30(2):138-140. https://doi.org/10. 3109/15360288.2016.1173761

7. Rice JB, White AG, Birnbaum HG, Schiller M, Brown DA, Roland CL (2012) A model to identify patients at risk for prescription opioid abuse, dependence, and misuse. Pain Med 13(9):11621173. https://doi.org/10.1111/j.1526-4637.2012.01450.x

8. Michna E, Ross EL, Hynes WL, Nedeljkovic SS, Soumekh S, Janfaza D, Palombi D, Jamison RN (2004) Predicting aberrant drug behavior in patients treated for chronic pain: importance of abuse history. J Pain Symptom Manag 28(3):250-258. https://doi.org/10. 1016/j.jpainsymman.2004.04.007

9. Montagna P (2007) Recent advances in the pharmacogenomics of pain and headache. Neurol Sci 28(Suppl 2):S208-S212. https://doi. org/10.1007/s10072-007-0778-0 
10. Aldrete JA, Zahler A, Aikawa JK (1970) Prevention of succinylcholine-induced hyperkalaemia by magnesium sulfate. Can Anaesth Soc J 17(5):477-484. https://doi.org/10.1007/ bf03004796

11. Gätke MR, Bundgaard JR, Viby-Mogensen J (2007) Two novel mutations in the BCHE gene in patients with prolonged duration of action of mivacurium or succinylcholine during anaesthesia. Pharmacogenet Genomics 17(11):995-999. https://doi.org/10. 1097/FPC.0b013e3282f06646

12. Beutler E (2008) Glucose-6-phosphate dehydrogenase deficiency: a historical perspective. Blood 111(1):16-24. https://doi.org/10. 1182/blood-2007-04-077412

13. Stein C (2016) Opioid Receptors. Annu Rev Med 67:433-451. https://doi.org/10.1146/annurev-med-062613-093100

14. Bozarth MA, Wise RA (1981) Heroin reward is dependent on a dopaminergic substrate. Life Sci 29(18):1881-1886. https://doi.org/ 10.1016/0024-3205(81)90519-1

15. Blum K, Kozlowski GP (1990) Ethanol and neuromodulators interaction: a cascade model of reward. In: Ollat $\mathrm{H}$, Parvez S, Parvez H (eds) Alcohol and Behavior. VSP Press, Utrecht

16. Blum K, Oscar-Berman M, Dinubile N, Giordano J, Braverman ER, Truesdell CE, Barh D, Badgaiyan R (2013) Coupling genetic addiction risk score (GARS) with electrotherapy: fighting iatrogenic opioid dependence. J Addict Res Ther 4(163):1000163. https:// doi.org/10.4172/2155-6105.1000163

17. Chen AL, Chen TJ, Waite RL, Reinking J, Tung HL, Rhoades P, Downs BW, Braverman E et al (2009) Hypothesizing that brain reward circuitry genes are genetic antecedents of pain sensitivity and critical diagnostic and pharmacogenomic treatment targets for chronic pain conditions. Med Hypotheses 72(1):14-22. https://doi. org/10.1016/j.mehy.2008.07.059

18. Blum K, Chen ALC, Thanos PK, Febo M, Demetrovics Z, Dushaj K, Kovoor A, Baron D et al (2018) Genetic addiction risk score (GARS) , a predictor of vulnerability to opioid dependence. Front Biosci (Elite Ed) 10:175-196

19. Blum K (2012) Neurogenetics and nutrigenomics of reward deficiency syndrome. In: Omics - biomedical perspectives and applications, vol 0. Taylor \& Francis CRC, Boca Raton, pp. 535-576

20. Blum K, Hauser M, Fratantonio J, Badgaiyan RD (2015) Molecular genetic testing in pain and addiction: facts, fiction and clinical utility. Addict Genet 2(1):1-5. https://doi.org/10.1515/addge-20150001

21. Blum K, Thanos PK, Badgaiyan RD, Febo M, Oscar-Berman M, Fratantonio J, Demotrovics Z, Gold MS (2015) Neurogenetics and gene therapy for reward deficiency syndrome: are we going to the Promised Land? Expert Opin Biol Ther 15(7):973-985. https://doi. org/10.1517/14712598.2015.1045871

22. Khantzian EJ (2013) Addiction as a self-regulation disorder and the role of self-medication. Addiction 108(4):668-669. https://doi.org/ 10.1111/add.12004

23. Borsook D, Linnman C, Faria V, Strassman AM, Becerra L, Elman I (2016) Reward deficiency and anti-reward in pain chronification. Neurosci Biobehav Rev 68:282-297. https://doi.org/10.1016/j. neubiorev.2016.05.033

24. Blum K, Smolen A, Haberstick BC, Smith DE, Febo M, Simpatico T, Han D, Villapiano A et al (2014) Addiction Risk Score (GARSRX ${ }^{\mathrm{TM}}$ ), Comprehensive Analysis of Reported Drugs $\left(\mathrm{CARD}^{\mathrm{TM}}\right)$ dopamine agonist therapy $\left(\mathrm{KB} 220 \mathrm{z}^{\mathrm{TM}}\right)$ embracing genetic prediction of addiction risk severity for pain treatment. ARSA Pain Meeting San Francisco

25. Blum K, Bowirrat A, Baron D, Lott L, Ponce JV, Brewer R, Siwicki D, Boyett B et al (2019) Biotechnical development of genetic addiction risk score (GARS) and selective evidence for inclusion of polymorphic allelic risk in substance use disorder (SUD). J Syst Integr Neurosci 6. https://doi.org/10.15761/JSIN.1000221

26. Fried L, Modestino EJ, Siwicki D, Lott L, Thanos PK, Baron D, Badgaiyan RD, Ponce JV et al (2019) Hypodopaminergia and "precision behavioral management" (PBM): it is a generational family affair. Curr Pharm Biotechnol 21:528-541. https://doi.org/10.2174/ 1389201021666191210112108

27. Pecina M, Love T, Stohler CS, Goldman D, Zubieta JK (2015) Effects of the $\mathrm{Mu}$ opioid receptor polymorphism (OPRM1 A118G) on pain regulation, placebo effects and associated personality trait measures. Neuropsychopharmacology 40(4):957-965. https://doi.org/10.1038/npp.2014.272

28. Casey BJ, Craddock N, Cuthbert BN, Hyman SE, Lee FS, Ressler KJ (2013) DSM-5 and RDoC: progress in psychiatry research? Nat Rev Neurosci 14(11):810-814. https://doi.org/10.1038/nrn3621

29. Blum K, Braverman ER, Wood RC, Gill J, Li C, Chen TJ, Taub M, Montgomery AR et al (1996) Increased prevalence of the Taq I A1 allele of the dopamine receptor gene (DRD2) in obesity with comorbid substance use disorder: a preliminary report. Pharmacogenetics 6(4):297-305

30. Arinami T, Iijima Y, Yamakawa-Kobayashi K, Ishiguro H, Ohtsuki T, Yanagi H, Shimakura Y, Ishikawa H et al (1999) Supportive evidence for contribution of the dopamine D2 receptor gene to heritability of stature: linkage and association studies. Ann Hum Genet 63(Pt 2):147-151. https://doi.org/10.1046/j.1469-1809. 1999.6320147.x

31. Arinami T, Itokawa M, Komiyama T, Mitsushio H, Mori H, Mifune H, Hamaguchi H, Toru M (1993) Association between severity of alcoholism and the A1 allele of the dopamine D2 receptor gene TaqI A RFLP in Japanese. Biol Psychiatry 33(2):108-114. https:// doi.org/10.1016/0006-3223(93)90309-2

32. Noble EP, Blum K, Ritchie T, Montgomery A, Sheridan PJ (1991) Allelic association of the D2 dopamine receptor gene with receptorbinding characteristics in alcoholism. Arch Gen Psychiatry 48(7): 648-654

33. Liu JH, Zhong HJ, Dang J, Peng L, Zhu YS (2015) Singlenucleotide polymorphisms in dopamine receptor D1 are associated with heroin dependence but not impulsive behavior. Genet Mol Res 14(2):4041-4050. https://doi.org/10.4238/2015.April.27.19

34. Peng S, Du J, Jiang H, Fu Y, Chen H, Sun H, Wang D, Yu S et al (2013) The dopamine receptor D1 gene is associated with the length of interval between first heroin use and onset of dependence in Chinese Han heroin addicts. J Neural Transm (Vienna) 120(11): 1591-1598. https://doi.org/10.1007/s00702-013-1029-6

35. Zhu F, Yan CX, Wen YC, Wang J, Bi J, Zhao YL, Wei L, Gao CG et al (2013) Dopamine D1 receptor gene variation modulates opioid dependence risk by affecting transition to addiction. PLoS One 8(8):e70805. https://doi.org/10.1371/journal.pone.0070805

36. Mayer-Blackwell B, Schlussman SD, Butelman ER, Ho A, Ott J, Kreek MJ, Zhang Y (2014) Self administration of oxycodone by adolescent and adult mice affects striatal neurotransmitter receptor gene expression. Neuroscience 258:280-291. https://doi.org/10. 1016/j.neuroscience.2013.10.062

37. Brewer AJ 3rd, Nielsen DA, Spellicy CJ, Hamon SC, Gingrich J, Thompson-Lake DG, Nielsen EM, Mahoney JJ 3rd et al (2015) Genetic variation of the dopamine transporter (DAT1) influences the acute subjective responses to cocaine in volunteers with cocaine use disorders. Pharmacogenet Genomics 25(6):296-304. https:// doi.org/10.1097/fpc.0000000000000137

38. Blum K, Oscar-Berman M, Stuller E, Miller D, Giordano J, Morse S, McCormick L, Downs WB et al (2012) Neurogenetics and nutrigenomics of neuro-nutrient therapy for reward deficiency syndrome (RDS): clinical ramifications as a function of molecular 
neurobiological mechanisms. J Addict Res Ther 3(5):139. https:// doi.org/10.4172/2155-6105.1000139

39. Palmer RH, Brick L, Nugent NR, Bidwell LC, McGeary JE, Knopik VS, Keller MC (2015) Examining the role of common genetic variants on alcohol, tobacco, cannabis and illicit drug dependence: genetics of vulnerability to drug dependence. Addiction 110(3):530-537. https://doi.org/10.1111/add.12815

40. Blum K, Wood RC, Braverman ER, Chen TJ, Sheridan PJ (1995) The D2 dopamine receptor gene as a predictor of compulsive disease: Bayes' theorem. Funct Neurol 10(1):37-44

41. Thanos PK, Volkow ND, Freimuth P, Umegaki H, Ikari H, Roth G, Ingram DK, Hitzemann R (2001) Overexpression of dopamine D2 receptors reduces alcohol self-administration. J Neurochem 78(5): 1094-1103

42. Blum K, Downs BW, Dushaj K, Li M, Braverman ER, Fried L, Waite R, Demotrovics Z et al (2016) The benefits of customized DNA directed nutrition to balance the brain reward circuitry and reduce addictive behavior. Precis Med (Bangalore) 1(1):18-33

43. Zhan J, Jordan CJ, Bi GH, He XH, Gardner EL, Wang YL, Xi ZX (2018) Genetic deletion of the dopamine D3 receptor increases vulnerability to heroin in mice. Neuropharmacology 141:11-20. https://doi.org/10.1016/j.neuropharm.2018.08.016

44. Wise EA, Price DD, Myers CD, Heft MW, Robinson ME (2002) Gender role expectations of pain: relationship to experimental pain perception. Pain 96(3):335-342. https://doi.org/10.1016/s03043959(01)00473-0

45. Fillingim RB, King CD, Ribeiro-Dasilva MC, Rahim-Williams B, Riley JL 3rd (2009) Sex, gender, and pain: a review of recent clinical and experimental findings. J Pain 10(5):447-485. https://doi. org/10.1016/j.jpain.2008.12.001
46. Pereira MP, Pogatzki-Zahn E (2015) Gender aspects in postoperative pain. Curr Opin Anaesthesiol 28(5):546-558. https://doi.org/ 10.1097/aco.0000000000000226

47. Vieira CMP, Fragoso RM, Pereira D, Medeiros R (2019) Pain polymorphisms and opioids: an evidence based review. Mol Med Rep 19(3):1423-1434. https://doi.org/10.3892/mmr.2018.9792

48. Chou WY, Yang LC, Lu HF, Ko JY, Wang CH, Lin SH, Lee TH, Concejero A et al (2006) Association of mu-opioid receptor gene polymorphism (A118G) with variations in morphine consumption for analgesia after total knee arthroplasty. Acta Anaesthesiol Scand 50(7):787-792. https://doi.org/10.1111/j.1399-6576.2006.01058.x

49. Chou WY, Hsu CJ (2020) A118G polymorphism of OPRM1 gene caused different morphine consumption in female patients after total knee replacement. J Orthop Sci. https://doi.org/10.1016/j.jos. 2020.05.017

50. Blum K, Modestino EJ, Gondré-Lewis MC, Neary J, Siwicki D, Hauser M, Barh D, Steinberg B et al (2017) Global opiod epidemic: doomed to fail without genetically based precision addiction ,medicine $\left(\operatorname{PAM}\left({ }^{\mathrm{TM}}\right)\right)$ : lessons learned from America. Precis Med (Bangalore) 2(1):17-22

51. Blum K, Febo M, Badgaiyan RD (2016) Fifty years in the development of a glutaminergic-dopaminergic optimization complex (KB220) to balance brain reward circuitry in reward deficiency syndrome: a pictorial. Austin Addict Sci 1(2):1006

Publisher's Note Springer Nature remains neutral with regard to jurisdictional claims in published maps and institutional affiliations.

\section{Affiliations}

\section{Mark Moran ${ }^{1,2} \cdot$ Kenneth Blum ${ }^{2,3,4,5,6,7,8,9,10}$ (D) - Jessica Valdez Ponce ${ }^{2} \cdot$ Lisa Lott $^{2} \cdot$ Marjorie C. Gondré-Lewis $^{11}$. Sampada Badgaiyan ${ }^{2} \cdot$ Raymond Brewer $^{2,8} \cdot$ B. William Downs ${ }^{9} \cdot$ Philip Fynman $^{12}$ - Alexander Weingarten ${ }^{12,13}$. Jean Lud Cadet ${ }^{14}$. David E. Smith ${ }^{15}$. David Baron ${ }^{5}$. Panayotis K. Thanos ${ }^{16} \cdot$ Edward J. Modestino $^{17}$. Rajendra D. Badgaiyan ${ }^{18,19,20,21,22} \cdot$ Igor Elman $^{23} \cdot$ Mark S. Gold $^{24}$}

1 Pain Consultants of San Antonio, San Antonio, TX, USA

2 Department of Nutrigenomics, Geneus Health, LLC, San Antonio, TX, USA

3 Department of Psychiatry, University of Vermont, Burlington, VT, USA

4 Division of Addiction Services, Dominion Diagnostics, North Kingston, RI, USA

5 Western University Health Science Centers, Graduate College, Pompano, CA, USA

6 Institute of Psychology, Eotvos Loránd University, Budapest, Hungary

7 Department of Psychiatry, Wright University Boonshoft School of Medicine, Dayton, OH, USA

8 The Kenneth Blum Behavioral and Neurogenetic Institute, (Division of Ivitalize Inc), Austin, TX, USA
9 Division of Nutrigenomics, Victory Nutrition International, LLC, Lederoch, PA, USA

10 Division of Clinical Neurology, Path Foundation NY, New York, NY, USA

11 Department of Anatomy, Developmental Neuro-PsychoPharmacology Laboratory, Howard University College of Medicine, Washington, DC, USA

12 Comprehensive Pain Management, Syosset, NY, USA

13 Department of Psychiatry, New York Medical College, Valhalla, NY, USA

14 Molecular Neuropsychiatry Branch, National Institutes of Health, Bethesda, MD, USA

15 Department of Pharmacology, College of Medicine, University of San Francisco, San Francisco, CA, USA 
16 Department of Psychology \& Behavioral Neuropharmacology and Neuroimaging Laboratory on Addictions (BNNLA), Research Institute on Addictions, University at Buffalo, Buffalo, NY, USA

17 Department of Psychology, Curry College, Milton, MA, USA

18 Department of Psychiatry, Icahn School of Medicine Mt Sinai, New York, NY, USA

19 Department of Psychiatry, South Texas Veteran Health Care System, Audie L. Murphy Memorial VA Hospital, San Antonio, TX, USA
Long School of Medicine, University of Texas Medical Center, San Antonio, TX, USA

21 Center For Psychiatric Medicine, Lawrence, MA, USA

22 Department of Psychiatry, Harvard School of Medicine, Boston, MA, USA

23 Department of Psychiatry, Harvard University School of Medicine, Cambridge, MA, USA

24 Department of Psychiatry, Washington University School of Medicine, St. Louis, MO, USA 